\title{
TRANSITORY PRÆCORDIAL PULSATION IN CORONARY OCCLUSION
}

\author{
BY \\ RUSTOM JAL VAKIL \\ From the Cardiological Department, King Edward Memorial Hospital, Bombay, India \\ Received July 12, 1955
}

The diagnostic value of clinical examination by inspection and palpation in organic diseases of the chest has been re-emphasized by Dressler $(1937 ; 1942)$.

In medical papers of the last three decades, there are only a few scattered references to the development of transitory præcordial pulsations, with or without aneurysm formation, during the acute or early phase of coronary occlusion. Aneurysm formation within one to three weeks of infarction has been reported in the past by Shookhoff and Douglas (1931), White (1945), Caplan and Sherwood (1949), and Vakil (1954). Pulsating aneurysmal bulges that are reversible and last for a few weeks have been reported by Libman and Sacks (1926) and Scherf and Erlsbacher (1934).

As far as can be ascertained no proper enquiry has been undertaken in the past to determine the incidence, characteristics, significance, and outcome of pulsatory phenomena in cases of acute coronary occlusion, and the present study was undertaken to fill in this gap.

\section{Material AND Method}

Since 1949, 193 cases of acute coronary occlusion have been carefully and repeatedly scrutinized throughout the initial four or five weeks of their illness, for the presence of pulsatory phenomena over the præcordium. Whenever observed, the main characteristics of these pulsations have been recorded and followed up. It has been customary at each examination, first to inspect the præcordial area carefully during the daytime from several different angles; later, the area has been palpated, percussed, and auscultated. In each case, a careful record has been maintained of the clinical history, physical signs, serial electrocardiographic records, routine blood counts, and erythrocyte sedimentation rates.

Of the 193 patients investigated, 172 were men and 21 women. Electrocardiographically, the

TABLE I

Distribution of CaSes According to Site of Infarction

\begin{tabular}{|c|c|c|c|c|c|c|c|}
\hline & All types & $\begin{array}{l}\text { Antero- } \\
\text { septal }\end{array}$ & $\begin{array}{l}\text { Extensive } \\
\text { anterior }\end{array}$ & $\begin{array}{l}\text { Localized } \\
\text { anterior }\end{array}$ & Posterior & $\begin{array}{l}\text { Antero- } \\
\text { posterior }\end{array}$ & $\begin{array}{c}\text { Miscel- } \\
\text { laneous and } \\
\text { indeterminate }\end{array}$ \\
\hline $\begin{array}{l}\text { Number of cases } \\
\text { of cor o n a r y } \\
\text { occlusion }\end{array}$ & 193 & $\begin{array}{c}48 \\
(25 \%)\end{array}$ & $\begin{array}{c}39 \\
(20 \%)\end{array}$ & $\begin{array}{c}23 \\
(12 \%)\end{array}$ & $\begin{array}{c}59 \\
(31 \%)\end{array}$ & $\begin{array}{c}5 \\
(3 \%)\end{array}$ & $\begin{array}{c}19 \\
(10 \%)\end{array}$ \\
\hline $\begin{array}{l}\text { Cases showing } \\
\text { anomalous pul- } \\
\text { sation }\end{array}$ & 11 & $\begin{array}{c}6 \\
(55 \%)\end{array}$ & $\begin{array}{c}4 \\
(36 \%)\end{array}$ & 0 & 0 & $\begin{array}{c}1 \\
(9 \%)\end{array}$ & 0 \\
\hline $\begin{array}{l}\text { Incidence of } \\
\text { pulsatory phe- } \\
\text { nomenon }\end{array}$ & $5 \cdot 7 \%$ & $12 \cdot 5 \%$ & $10 \cdot 3 \%$ & - & - & $20 \%$ & - \\
\hline
\end{tabular}


following groups of cases were recognizable, viz., (1) extensive anterior wall infarcts, 39 cases; (2) extensive anterior wall infarcts with septal involvement, 48 cases; (3) localized anterior wall infarcts, 23 cases; (4) posterior wall infarcts, 59 cases; (5) anterior and posterior wall infarcts, 5 cases; and (6) miscellaneous and indeterminate group of infarcts, 19 cases (Table I). Doubtful cases and those of subendocardial and subepicardial infarction were excluded from this study.

\section{RESULTS}

Anomalous præcordial pulsations, during the acute phase of the coronary attack, were observed in $11(5.7 \%)$ of the 193 cases. Of the 11 cases, ten were men and one a woman, ranging in age from 44 to 75 years with an average of 59 years. Four were hypertensive, 1 diabetic, and 3 hypertensive and diabetic; the high incidence of hypertension $(64 \%)$ and diabetes $(36 \%)$ was noteworthy. While two of the cases were having their second attack of coronary occlusion, in the remaining nine it was the first attack.

Clinical Characteristics. The anomalous pulsation was located medial to and slightly above the level of the customary apex beat in all 11 cases. In 7, the apex beat was neither visible nor palpable.

On the basis of their relationship to the apex beat, three main types of pulsations were recognized (Fig. 1), viz., (1) Type A (7 cases or 64\%) with a single præcordial pulsation, 2 to $6 \mathrm{~cm}$. in
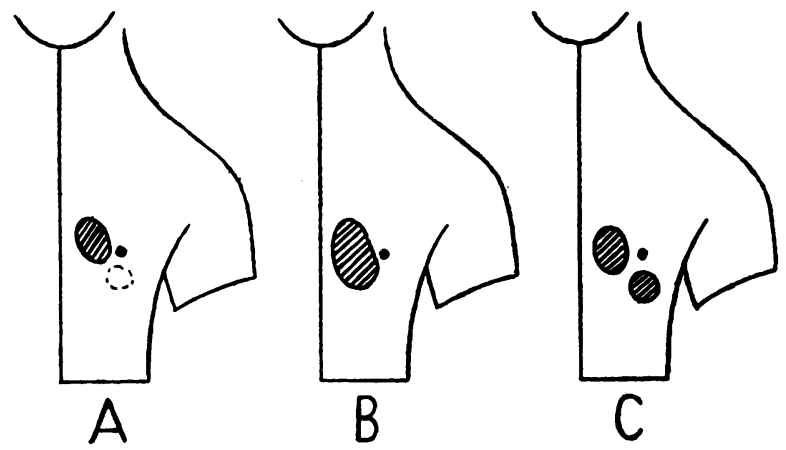

Fig. 1.-Three types of anomalous præcoridal pulsation. A, B, and C.

diameter, rather internal to and above the apex beat which was absent; (2) Type B (3 cases or $27 \%$ ) with a single wide area of pulsation, 6 to $7 \mathrm{~cm}$. in diameter, caused by the fusion or confluence of the anomalous pulsation with a visible and palpable apex beat; (3) Type $\mathrm{C}$ ( 1 case or $9 \%$ ) with two distinct areas of pulsation (the so-called " double impulse"), the apex beat and para-apical area of pulsation being separated by a zone of no pulsation.

The anomalous pulsation was observed for the first time during the first week of illness in 7 cases $(64 \%)$, during the second week in $3(27 \%)$, and during the third in 1 case $(9 \%)$. With two exceptions (Cases 5 and 11), where the pulsation became permanently established as part of a ventricular aneurysm, it was transitory, lasting for from 4 to 24 days with an average of 13 days.

The following phenomena were observed during the time of the anomalous pulsation, viz., transient auricular fibrillation in one, ectopic beats in two, gallop rhythm in five, and " tic tac" rhythm in three cases. Transitory systolic murmurs over the area of pulsation were noted in two cases.

Electrocardiographic Correlation. On the basis of electrocardiographic localization of myocardial infarcts, the following groups of cases were recognizable (Table I), viz., (1) extensive anterior wall infarcts (4 cases), (2) anteroseptal infarcts (6 cases) and (3) anteroposterior infarcts ( 1 case). No case belonged to the category of localized anterior wall or posterior wall infarction.

It will be obvious from Table I that the incidence of anomalous præcordial pulsation in acute 
coronary occlusion depends greatly on the site of infarction, being more common in cases of extensive anterior wall involvement with or without septal involvement.

Prognosis. Whilst the immediate mortality (within 8 weeks of onset of the acute attack) for the coronary group (193 cases), was 15 per cent, it was 27 per cent ( 3 deaths) for the smaller group of 11 cases with anomalous præcordial pulsations. Paradoxically enough, both cases with second attacks of coronary occlusion recovered, while 3 of the 9 with first attacks proved fatal. Further analyses have failed to establish any relationship between factors like time of onset, duration, extent and type of pulsation, and the immediate outcome of the case.

A Clinical Sign of Value. The clinical sign described here, appears to have some value in diagnosis and prognosis. This diagnostic value was confirmed in two of my cases of chest pain where a diagnosis of myocardial infarction was made, merely on the basis of this sign, several days before cardiographic confirmation. Furthermore, since every case in my series of acute coronary occlusion with this sign was subsequently proved to be one of extensive anterior wall infarction, with or without septal involvement, the localizing value of the sign appears obvious. It appears that in all cases of severe chest pain or of suspected coronary occlusion, the development of an anomalous pulsation over the præcordium is sufficient justification for a presumptive diagnosis of extensive myocardial infarction involving the anterior wall of the heart.

A fatal termination within six weeks of onset of the acute attack was observed in 15 per cent of all cases (193 cases) of coronary occlusion and in 27 per cent of cases showing anomalous præcordial pulsations (11 cases). In view of the higher mortality rate of the latter group, one feels justified in regarding the sign as one of bad prognostic significance. Also, the possibility of aneurysm formation in the near future should be considered as illustrated by Cases 5 and 11 of this series.

\section{Summary AND CONCluSIONS}

Of a series of 195 cases of acute coronary occlusion where repeated observations and proper follow-up were possible, 11 cases $(5 \cdot 7 \%)$ showed at some time or other during the initial four weeks of their illness, a visible and palpable area of pulsation over the præcordium. Located mesial to and above the level of the apex beat, 2.5 to $7 \mathrm{~cm}$. in diameter, the pulsatory phenomenon was transitory in nine and persistent as a parietal or ventricular aneurysm in two of the cases. On the basis of their relationship to the apex beat, three main types of pulsations were recognizable.

Extensive anterior wall myocardial infarction with or without septal involvement was demonstrable in all the cases, electrocardiographically. Evidence is presented to show that the clinical sign described here has some value in the early diagnosis, localization, and prognosis of myocardial infarcts.

\section{REFERENCES}

Caplan, M., and Sherwood, P. M. (1949). New England J. Med., 240, 629.

Dressler, W. (1937). Arch. intern. Med., 60, 225, 437, 441, 654, and 663.

(1942). Clinical Cardiology. 1st ed., New York and London, Paul B. Hoeber, Inc.

Libman, E., and Sacks, B. (1926). Amer. Heart J., 2, 321.

Scherf, D., and Erlsbacher, O. (1934). Med. Klin., 30, 1687.

Shookhoff, C., and Douglas, A. H. (1931). Amer. Heart J., 7, 95.

Vakil, R. J. (1954). Medicine (India), 1, 1.

White, P. D. (1945). Heart Disease. 3rd ed., New York, MacMillan Co. 